\section{artelogie}

\section{Artelogie}

Recherche sur les arts, le patrimoine et la littérature de l'Amérique latine

10 | 2017

Après le paysage : l'art, l'inscription et la représentation de la nature en Amérique latine aujourd'hui

\title{
Vue d'ensemble
}

Jacques Leenhardt, Maria José de Azevedo Marcondes et Catalina Valdés

\section{CpenEdition}

Journals

Édition électronique

URL : http://journals.openedition.org/artelogie/912

DOI : 10.4000/artelogie.912

ISSN : 2115-6395

Éditeur

Association ESCAL

Référence électronique

Jacques Leenhardt, Maria José de Azevedo Marcondes et Catalina Valdés, « Vue d'ensemble », Artelogie [En ligne], 10 | 2017, mis en ligne le 05 avril 2017, consulté le 23 septembre 2020. URL

http://journals.openedition.org/artelogie/912 ; DOI : https://doi.org/10.4000/artelogie.912

Ce document a été généré automatiquement le 23 septembre 2020.

Association ESCAL 


\title{
Vue d'ensemble
}

\author{
Jacques Leenhardt, Maria José de Azevedo Marcondes et Catalina Valdés
}

1 Artelogie publie son dixième numéro avec une série de nouveautés éditoriales dont nous avons la satisfaction de les partager avec nos lecteurs. À partir de ce numéro, la revue intègrera la plateforme de périodiques indexés dans le domaine des sciences humaines et sociales françaises - Revues.org, qui inclut le portail OpenEdition. Outre ces potentialités, il faut signaler qu'avec ce dixième numéro d'Artelogie débute une nouvelle collaboration avec la revue Critique d'Art - publication issue des Archives de la critique d'art de Rennes. À travers cette collaboration, les recensions d'ouvrages inclues dans ce numéro et dans les prochains seront traduites en français et publiées dans la revue citée. Nous souhaitons souligner que l'intégration à Revues.org ainsi que la collaboration à la revue Critique d'Art représentent une reconnaissance du travail universitaire et éditorial développé par la revue Artelogie ces dernières années. S'inscrivant dans un réseau de publications numériques, la revue élargit non seulement sa diffusion mais concède une plus grande visibilité aux recherches en histoire de l'art et de la culture latino-américaine dans le cadre universitaire international et plus spécifiquement français.

2 Ce nouveau numéro propose une plateforme poétique et critique d'une cartographie d'artistes, d'images et d'idées qui abordent la représentation et l'inscription de la nature en Amérique Latine dans l'art. Ce sujet d'étude a engagé chercheurs, artistes et spécialistes des diverses disciplines liées à la production de paysages à proposer leur collaboration.

3 Les hypothèses de départ présentées dans la revue Artelogie partent de l'idée suivant laquelle les représentations artistiques de la nature en Amérique Latine révèlent une construction culturelle nuancée par les processus de colonisation du territoire par les Européens depuis le $\mathrm{XV}^{\mathrm{e}}$ siècle et par la formation postérieure des états modernes au début du XIX ${ }^{e}$ siècle. Les images de milieux naturels et culturels produites durant cette période, se prévalant d'appartenir à la peinture de paysage et aux autres formes de représentation, sont le reflet des expériences directes ou d'expériences octroyées par les artistes, principalement étrangers ayant contribué à la création d'un imaginaire déterminé par l'exotique, l'exubérant, le sublime et le pittoresque. Par l'appropriation 
de formes esthétiques de tradition européenne, les images de la nature américaine entrent en résonance, dialoguent ou se combinent avec la culture matérielle et immatérielle locale. Ainsi, les modèles épistémologiques (esthétiques et scientifiques) se sont-ils formés par l'appropriation d'une réalité spécifique de la région.

4 À l'issue d'un positionnement critique postcolonial, des œuvres d'art ainsi que des études portant sur une reconsidération de l'histoire sont apparues ces dernières années. Ces travaux révèlent le pouvoir colonisateur que peuvent exercer les représentations visuelles de la nature américaine produites par (et en principe aussi pour) le regard européen. Parallèlement, ladite révision critique a mis en lumière les déplacements et les interférences cognitives et esthétiques que la rencontre entre l'Europe et l'Amérique a provoqué et ce, réciproquement, transformant de manière déterminante la relation des sujets avec leur milieu naturel.

Dans le cadre des études menées en histoire de l'art latino-américaine, la peinture de paysage du XIX ${ }^{e}$ siècle représente l'un des meilleurs artefacts permettant de revoir les fonctions de l'image dans les processus de formation des identités sociales. Cette perspective ne perd pas de vue les interrogations contingentes que suppose le paysage en tant que genre pictural et en tant que manifestation d'un processus plus vaste qui a mené les imaginaires et les territoires vers les canons d'une modernité séculaire. En d'autres termes, la peinture de paysage a intégré les modalités de représentations de lieux, jouant non seulement un rôle remarquable dans les processus de formation des identités nationales mais aussi soulevant des questions contingentes visibles à travers un regard contemporain et critique.

6 Jusqu'à la fin du XIX et au début du XX $\mathrm{XX}^{\mathrm{e}}$ siècle, les écrivains et les artistes locaux se sont concentrés sur le paysage s'essayant à de nouvelles formes et de nouveaux styles et ayant recours à l'abstraction, aux matérialités et aux techniques non conventionnelles. Par le biais d'images aux contours politisés, une identité locale s'est réaffirmée et ce, grâce à une vision renouvelée des notions de nationalisme, d'indianisme ou de latino-américanisme. À travers elles, la nature semble occuper une fonction de matière-première garante d'une utopie modernisatrice.

7 Actuellement, en raison des contingences d'une nature menacée - et menaçante - il s'avère nécessaire d'enquêter sur la relocalisation de la condition humaine dans le milieu naturel et de relativiser l'opposition global/local; des dichotomies qui entretenaient l'ordre moderne. Tant les catastrophes dites naturelles récurrentes dont les causes et effets prennent racines dans la société et ayant acquis au cours de ce dernier siècle une dimension globale - que le développement récent des théories sociales et scientifiques qui détricotent les limites entre nature et culture, exigent de l'art contemporain - et des lectures contemporaines de l'art - qu'il reconsidère ses propres conditions géopolitiques, impliquant une conceptualisation renouvelée de la notion même de paysage.

8 La présente édition offre de multiples entrées aux problématiques précédemment évoquées, sans toutefois les circonscrire par des limites géopolitiques ou temporelles particulières, d'autant plus qu'elles ne correspondent pas toutes à une même discipline ou pratique culturel. Les thèmes abordés dans les articles, les entrevues, les comptes rendus d'expositions et les recensions d'ouvrages réunis dans cette édition nécessitent un regard transdisciplinaire. Alors même que les textes s'appuient sur des cas particuliers, leurs auteurs établissent des relations qui explicitent la portée globale des phénomènes abordés. 
9 Si la perspective sociale demeure présente dans les articles, ceux-ci ont été organisés chronologiquement de telle sorte qu'ils rendent compte du développement historique des représentations de la nature. Débutant par les constructions picturales des paysages, les articles de Carla Hermann et María Beatriz H. Carrión abordent les œuvres et les artistes itinérants qui, au fur et à mesure de leurs voyages, acquièrent de nouveaux sens. L'article de Jens Andermann intègre cette même dimension dynamique des styles architectoniques. Dans les trois cas cités, ces auteurs explicitent les portées idéologiques des manifestations qui, de manière conventionnelle, auraient dues être considérées comme représentatives et officielles, hors d'une nation ou d'une localisation particulière.

La géographe et historienne de l'art brésilienne Carla Herman étudie les panoramas de la ville de Rio de Janeiro faites par l'artiste français Félix Émile Taunay et le britannique Robert Burford, exposés respectivement à Paris et à Londres. L'auteure analyse les différentes stratégies mises au point par ces artistes pour représenter la nature dans un paysage construit et exposé en territoire européen, cherchant alors à comprendre les stratégies et les dynamiques du regard de l'autre dans un double sens, impliquant une condition étrangère des artistes et les lieux d'expositions.

11 Concernant la question de la construction culturelle des identités et des nationalités dans les représentations de la nature, l'historienne de l'art équatorienne María Beatriz H. Carrión analyse dans son article « Seduzindo al mundo : las imágenes de El Salvador en Chicago " les représentations du paysage de la côte de l'Équateur dans le livre $E l$ Salvador en Chicago, une œuvre commémorative de la participation de ce pays à l'Exposition de Chicago en 1893 ; elle concluait ainsi qu'à travers la construction des paysages était recherchée la construction d'un pays moderne et d'une "nature artificialisée » qui s'éloignait des représentations picturales de l'Équateur répondant au sublime naturel propre à l'art du milieu du XIX ${ }^{e}$ siècle.

De son côté, l'essayiste allemand Jens Andermann, spécialiste des études culturelles latino-américaines, analyse la construction sociale du paysage de la Patagonie argentine dans son texte "Estilo austral : paisaje, arquitectura y regionalismo nacionalizador en el Parque Nacional Nahuel Huapi (1934-1943) ». À partir de l'étude du style architectural et de la configuration du paysage dans le développement du tourisme de la première moitié du $\mathrm{XX}^{\mathrm{e}}$ siècle, Andermann identifie des dynamiques colonialistes par l'appropriation du territoire et révèle les contradictions d'un ordre moderne qui s'établit sous diverses formes, mais qui s'impose aussi à travers les lois du marché, ainsi que la privatisation des coutumes et du goût dans des régions éloignées de la ville.

Les travaux qui abordent les manifestations artistiques contemporaines présentent une perspective critique postcoloniale esthétiquement parlant, ainsi qu'une éthique qui conditionne les productions littéraires, visuelles et curatoriales, devenant les expériences d'un monde naturel et culturel essentiellement politiques. L'article de l'auteure et traductrice argentine Azucena Galenttini propose une réflexion concernant les évocations poétiques de la nature caribéenne dans les œuvres d'auteurs écrivant en langue anglaise, se rapprochant d'une imagerie du paysage qui trouve ses origines dans le déracinement et l'acculturation. L'analyse de Azucena met en évidence les opérations de dislocation d'une vision exotique et idéalisée de la production littéraire précédente (une production considérée comme nationale et authentique), et qui correspond aux 
dynamiques d'exploration humaine et artificielle du territoire comme autant de marques de cette poétique caribéenne contemproaine dans la langue anglaise.

Dans le même ordre d'idées, le chercheur et critique brésilien Fábio Zucker écrit sur l'œuvre de Daniel Steegmann Mangrané, artiste espagnol vivant au Brésil. Zucker met en relation les interventions subtiles de Mangrané avec les modalités de perception et rapprochement du monde indigène de l'Amazonas, guidé par des observations anthropologiques. L'interdisciplinarité présente en toile de fond dans l'appel à contribution de ce numéro se matérialise dans cet article.

15 Le dossier d'articles s'achève sur le texte de l'historienne de l'art mexicaine Aracelli Barbosa Sánchez, «Representación del paisaje americano desde la perspectiva de la sustentabilidad », dans lequel elle dresse une cartographie d'artistes, de chercheurs et de spécialistes du paysage d'Amérique Latine, attachés à une conscience écologique relative aux changements climatiques, qualifiés de catastrophes environnementales ou, d'une autre manière, de processus d'anthropisation qui marque notre contemporanéité.

Profitant des événements survenus concomitamment à l'élaboration de ce numéro, l'équipe éditoriale a reçu et mis en place une série de collaborations sous forme d'entretiens filmés, de compte rendus d'expositions et de recensions de publications. L'exposition L'ateliê tropical: Jean-Baptiste Debret, peintres, écrivains et savants français au Brésil (1816-1850) commémore le bicentenaire de la Mission Artistique Française au Brésil. Présentée au Musée Castro Maya à Rio de Janeiro et à la Maison de l'Amérique Latine à Paris, cette exposition est expliquée par son commissaire et sociologue de l'art français, Jacques Leenhardt. Le film de l'exposition et l'entretien se complètent avec la recension - élaborée par le curator et historien de l'art carioca Raphael Fonseca - de la nouvelle édition de l'œuvre de Jean-Baptiste Debret, Voyage pittoresque et historique au Brésil dont la préface revient au même Leenhardt.

Réalisé par l'historienne de l'art Marta Penhos, l'entretien avec le peintre argentin Leonel Luna à l'occasion de l'exposition Paisajes Americanos (dont le commissariat revient à Cecília Cavanagh - Directrice du Pavillon des Beaux-Arts de l'Université Catholique de Buenos Aires, 2016) aborde le paysage hétérotopique, le pittoresque et le sublime revisités sous une perception toute contemporaine, et plus précisément dans l'analyse de l'œuvre Limites, articulant dans le texte de Marta Penhos le passé avec le présent et l'histoire sociale du pays. Dans l'entretien, l'auteure analyse le thème du paysage pour l'artiste en tant qu'idée qui se transforme continuellement et l'apposition du Paysage Américain en tant qu'articulation entre géographie, territoire et lieux.

18 L'historien de l'art brésilien Renato Menezes réalise un entretien avec l'historien Luis Márquez, spécialiste de l'art de la renaissance, qui, depuis quelques années, entreprend des recherches sur l'histoire récente du capitalisme global et les conditions de crise environnementale, orientant ses capacités en tant que chercheur et essayiste vers le développement d'une écriture politique et impérative.

19 Tenant compte de la contingence de la scène artistique actuelle, la critique d'art et professeur brésilienne Maria José Marcondes présente une analyse des fondements conceptuels du commissariat de la $32^{2 \text { ème }}$ Biennal de São Paulo (2016), abordant les œuvres de quelques auteurs ibéro-américains depuis une perspective post-colonialiste de la culture et identifiant dans certains travaux artistiques exposés dans cette édition de la Biennale, la mise en marche d'une "épistémologie du sud ", entendue comme le 
sauvetage de cultures traditionnelles et la proposition de poétiques visuelles relatives à la thématique de l'urgence écologique.

Le commissaire et critique Gabriel Bogossian analyse les expositions A Queda do Céu (2015) et Resistências Contemporâneas (2016) - avec le commissariat de Moacir dos Anjos dans son texte "Um museu ausente: curadoria independente e ativismo indigenista ", abordant la question posée dans ce dossier thématique sur les pratiques artistiques, anthropologiques et/ou historiques autour des relations entre nature et culture dans les sociétés indigènes de l'Amérique Latine.

L'actualité des questions traitées dans ce dossier, concernant les travaux de poétiques visuelles dans lesquels les paysages hétérotopiques, le pittoresque et le sublime sont revisités à travers un regard contemporain, est mise en évidence à travers la recension de Maria Teresa Márquez de l'exposition Hidropoética, expedições Antárticas, avec le commissariat de Ricardo Mancillas Garay, (2016/2017) du Musée d'Art contemporain de Santiago (Chili), dans laquelle divers artistes intègrent la thématique de l'identité, du territoire et du paysage.

Enfin, deux autres recensions abordent les récentes publications qui élargissent le champ des relations entre art, nature et culture, suivant des perspectives historiques, iconographiques et anthropologiques. Élaborée par l'historienne de l'art chilienne Catalina Valdés, la première recension explique le catalogue de l'exposition «Picturing the Americas. Landscape painting from Tierra del Fuego to the Artics " (2015); la seconde, de F ábio Zucker, présente le livre de Déborah Danowski et Eduardo Viveiros de Castro - Há um mundo por vir? Ensaios sobre medos e fins apresenta uma reflexão dos autores sobre o pensamento ameríndio (2014) - qui étaye les différents arguments évoqués par les auteurs participant à ce dossier.

\section{AUTEURS}

\section{JACQUES LEENHARDT}

EHESS

MARIA JOSÉ DE AZEVEDO MARCONDES

Instituto de Artes, UNICAMP

CATALINA VALDÉS

EHESS/IDAES-Universidad Nacional de San Martín 